\title{
Knowledge, attitudes and beliefs about vaccination in primary healthcare workers involved in the administration of systematic childhood vaccines, Barcelona, 2016/17
}

Camila Andrea Picchio ${ }^{1,3,4}$, Mireia Garcia Carrasco ${ }^{1,4}$, Maria Sagué-Vilavella ${ }^{2,3,4}$, Cristina Rius $^{2,4,5}$

1. Servei Programes i Intervencions Preventives, Agencia de Salut Publica de Barcelona, Barcelona, Spain

2. Servei d’Epidemiologia, Agencia de Salut Publica de Barcelona, Barcelona, Spain

3. Universitat Pompeu Fabra, Barcelona, Spain

4. Universitat Autonoma de Barcelona, Barcelona, Spain

5. CIBER Epidemiología y Salud Pública (CIBERESP), Instituto Carlos III, Madrid, Spain

Correspondence: Mireia Garcia Carrasco (mgcarras@aspb.cat)

Citation style for this article:

Picchio Camila Andrea, Carrasco Mireia Garcia, Sagué-Vilavella Maria, Rius Cristina. Knowledge, attitudes and beliefs about vaccination in primary healthcare workers involved in the administration of systematic childhood vaccines, Barcelona, 2016/17. Euro Surveill. 2019;24(6):pii=1800117. https://doi.org/10.2807/15607917.ES.2019.24.6.1800117

Background: Healthcare professionals are a reliable and impactful source of information on vaccination for parents and children. Objectives: We aimed to describe the knowledge, attitudes and beliefs primary care professionals involved in administration of childhood vaccines in Barcelona have about vaccines and vaccination. Methods: In 2016/17, surveys were administered in person to every public primary care centre (PCC) with a paediatrics department $(n=41)$. Paediatricians and paediatric nurses responded to questions about disease susceptibility, severity, vaccine effectiveness, vaccine safety, confidence in organisations, key immunisation beliefs, and how they vaccinate or would vaccinate their own children. We used standard descriptive analysis to examine the distribution of key outcome and predictor variables and performed bivariate and multivariate analysis. Results: Completed surveys were returned by 277 ( $81 \%)$ of 342 eligible participants. A quarter of the respondents reported doubts about at least one vaccine in the recommended childhood vaccination calendar. Those with vaccine doubts chose the response option 'vaccine-hesitant' for every single key vaccine belief, knowledge and social norm. Specific vaccine knowledge was lacking in up to $40 \%$ of respondents and responses regarding the human papilloma virus vaccine were associated with the highest degree of doubt. Being a nurse a risk factor for having vaccine doubts (adjusted odds ratio $(\mathrm{ORa})=2.0$; 95\% confidence interval (95\% Cl): 1.1-3.7) and having children was a predictor of lower risk (ORa $=0.5 ; 95 \% \mathrm{Cl}: 0.2-$ 0.9). Conclusions: Despite high reported childhood immunisation rates in Barcelona, paediatricians and paediatric nurses in PCC had vaccine doubts, especially regarding the HPV vaccine.

\section{Introduction}

The term vaccine hesitancy (VH) was defined in 2012 by the World Health Organization's (WHO) Strategic Advisory Group of Experts (SAGE) on Immunization as 'delay in acceptance or refusal of vaccination despite availability of vaccination services. Vaccine hesitancy is complex and context specific, varying across time, place and vaccines. It is influenced by factors such as complacency, convenience and confidence' [1].

During the last decade, groups or subpopulations where vaccination coverage is below the required threshold because of $\mathrm{VH}$ have been associated with outbreaks and the reappearance of vaccine-preventable diseases, like measles [2]. In 2017, the WHO reported a total of 21,315 cases of measles and 35 deaths in the European Region of the WHO alone, representing an increase of $400 \%$ compared with the previous year [3]. In Barcelona, however, the situation was more stable despite 46 confirmed measles cases that originated from imported cases in the same year $[4,5]$.

Notwithstanding the impact of the media and the easy access to the Internet, which can contribute positively or negatively [6] to the acceptance of childhood immunisation, healthcare professionals (HCPs) have repeatedly been identified as the most reliable and impactful source of information on vaccination for parents and their children [2,7-9]. Sixty-nine per cent of Spanish families identified their paediatrician as the most 
Paediatric health professionals who responded 'late', 'doubts', or 'no' to vaccinating their own children, survey about vaccine knowledge, attitudes and beliefs, Barcelona, 2016/17 $(n=277)$

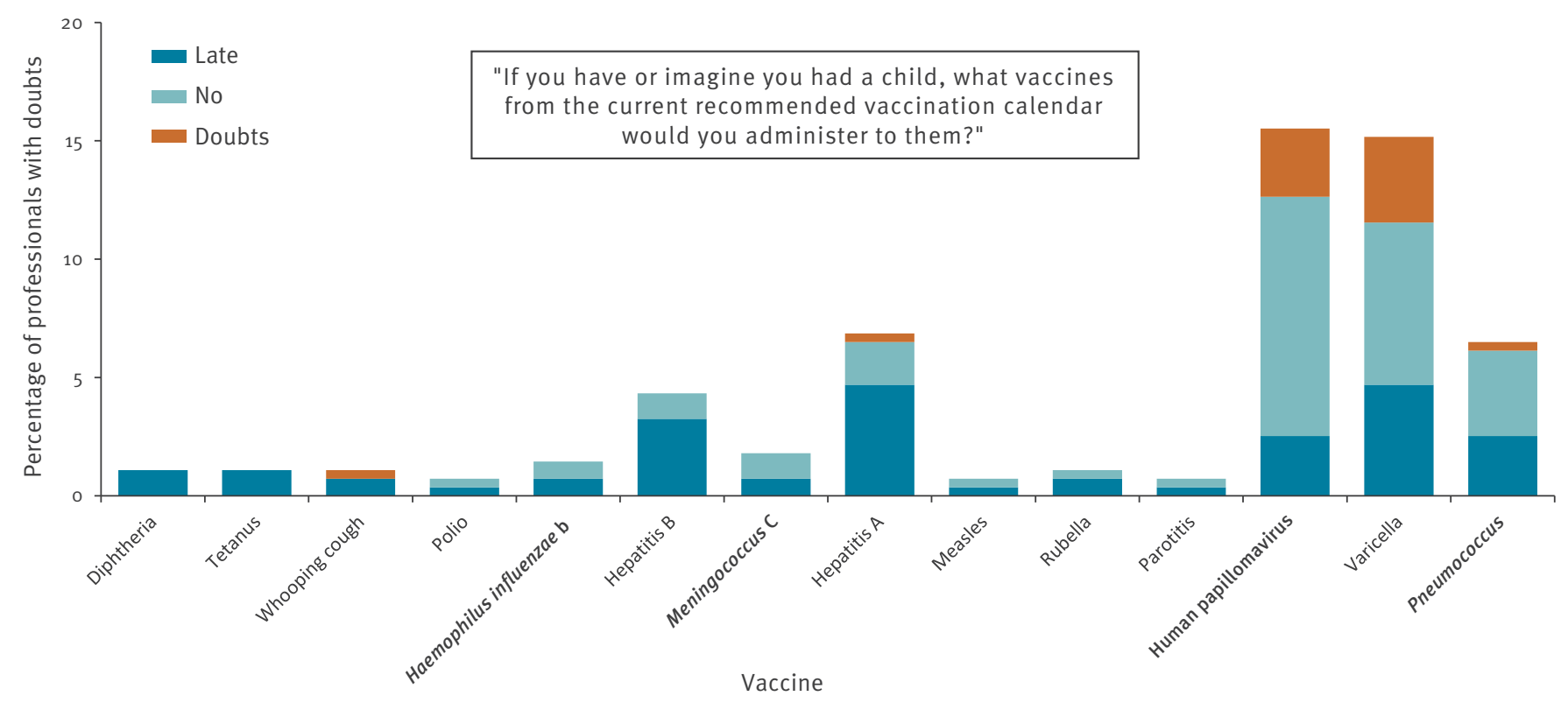

important source regarding vaccines [10]. Nonetheless, although it is internationally recommended [8] to work with this population to counter $\mathrm{VH}, \mathrm{HCPs}$ in the region of Catalonia in Spain have not been studied.

Given that VH has been described among European vaccine providers [11], it is of the utmost importance to address the loss of confidence in vaccines in this population. Entire vaccination programmes could be jeopardised if healthcare professionals' recommendations to immunise children are deficient as a result of VH [7]. Faced with this situation at the European level, and in spite of adequate vaccine coverage, the Public Health Agency of Barcelona (ASPB) launched in 2016 a line of research to monitor $\mathrm{VH}$ in HCPs and study its determinants in Barcelona. The main objective of this study was to describe the knowledge, attitudes and beliefs about vaccines among professionals who are directly involved in the administration of systematic childhood vaccines in the public health system of the city.

\section{Methods}

This investigation is an observational cross-sectional study consisting of data collected through a structured survey.

\section{Population surveyed}

In Barcelona, systematic childhood vaccination is recommended and administered by paediatric health professionals (paediatricians and paediatric nurses). The public health system coversmore than $90 \%$ of all childhood vaccinations in the city. The study population enrolled were HCPs who were directly involved in the administration of systematic childhood vaccines in public primary care centres (PCC) in Barcelona. Family doctors or practitioners who specialise in fields not related to paediatrics and nurses who were not directly involved in the administration of childhood vaccines were excluded. Students, residents and temporary substitutes of any kind were also excluded.

Of the 54 PCC serving the city of Barcelona, 41 have a paediatrics department with overall 342 professionals.

\section{Questionnaire}

A questionnaire was developed following available literature [12-14]. The questionnaire was translated into Spanish and Catalan and culturally adapted using the cognitive debriefing method [15]. Cognitive debriefing is a process where representatives of the target population actively test the translated questionnaires to determine whether respondents would understand the questionnaire as easily as the English version would be understood [16].

Respondents answered questions about disease susceptibility, disease severity, vaccine effectiveness, vaccine safety, who benefits from childhood immunisations, key immunisation beliefs, whether or not they had children, how they vaccinated or would vaccinate their own children, and whether they felt they had enough information and tools in order to adequately respond to vaccine-hesitant parents.

\section{Administration}

Questionnaires were self-administered by the HCPs at the PCC during a date and time that was previously agreed between the investigators and contact person from each centre. Contact with centres began in March 


\section{FIGURE 2}

Disease susceptibility and severity perceived by paediatric health professionals, survey about vaccine knowledge, attitudes and beliefs, Barcelona, 2016/17 $(\mathrm{n}=277)$

"What probability do you consider that an unvaccinated or unimmunised child has of contracting the following illnesses? Consider a 10-year period in the current Spanish context."

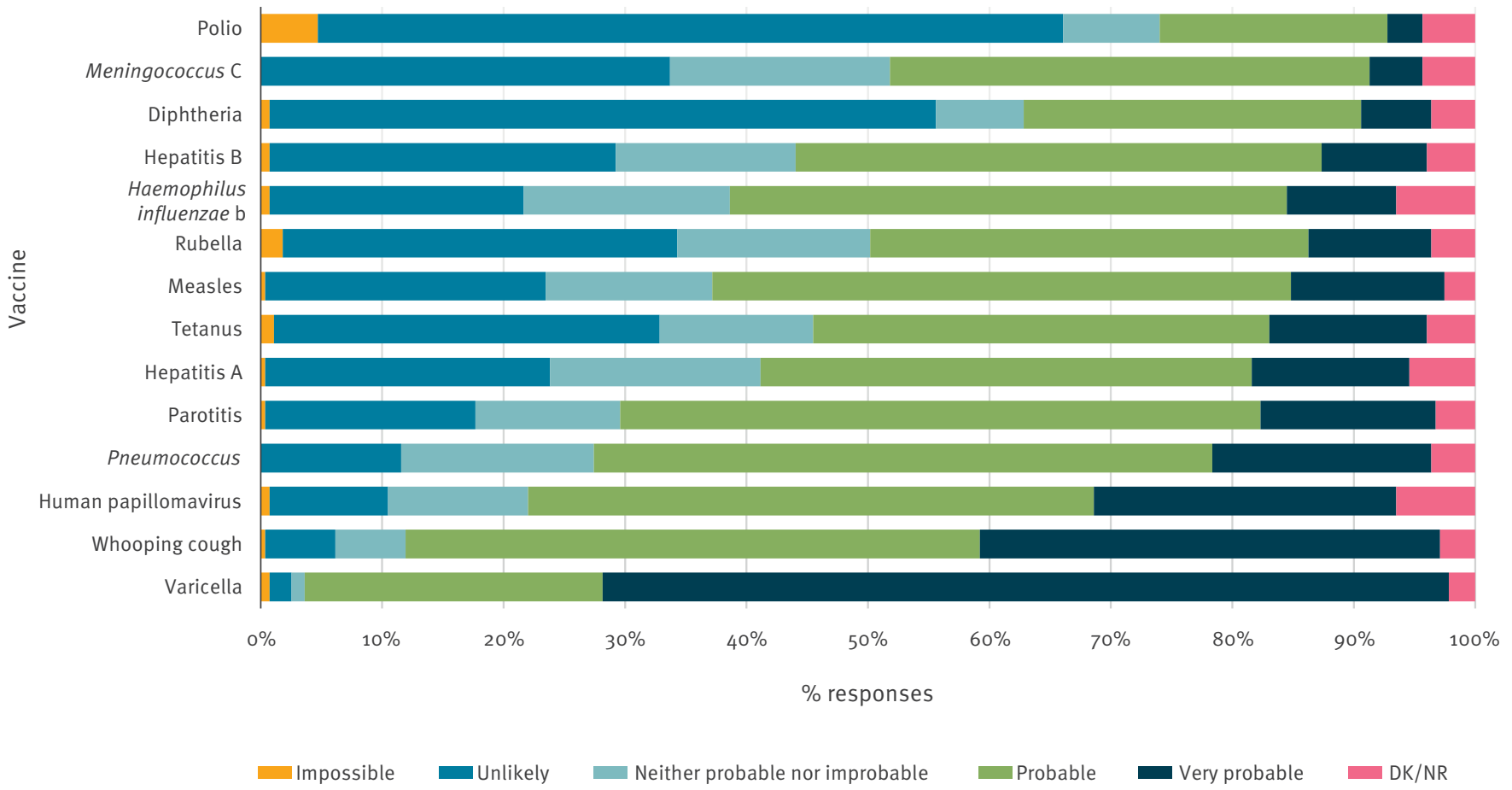

"How severe do you consider it to be for an unimmunised and unvaccinated 8-year-old to become ill with the following diseases?"

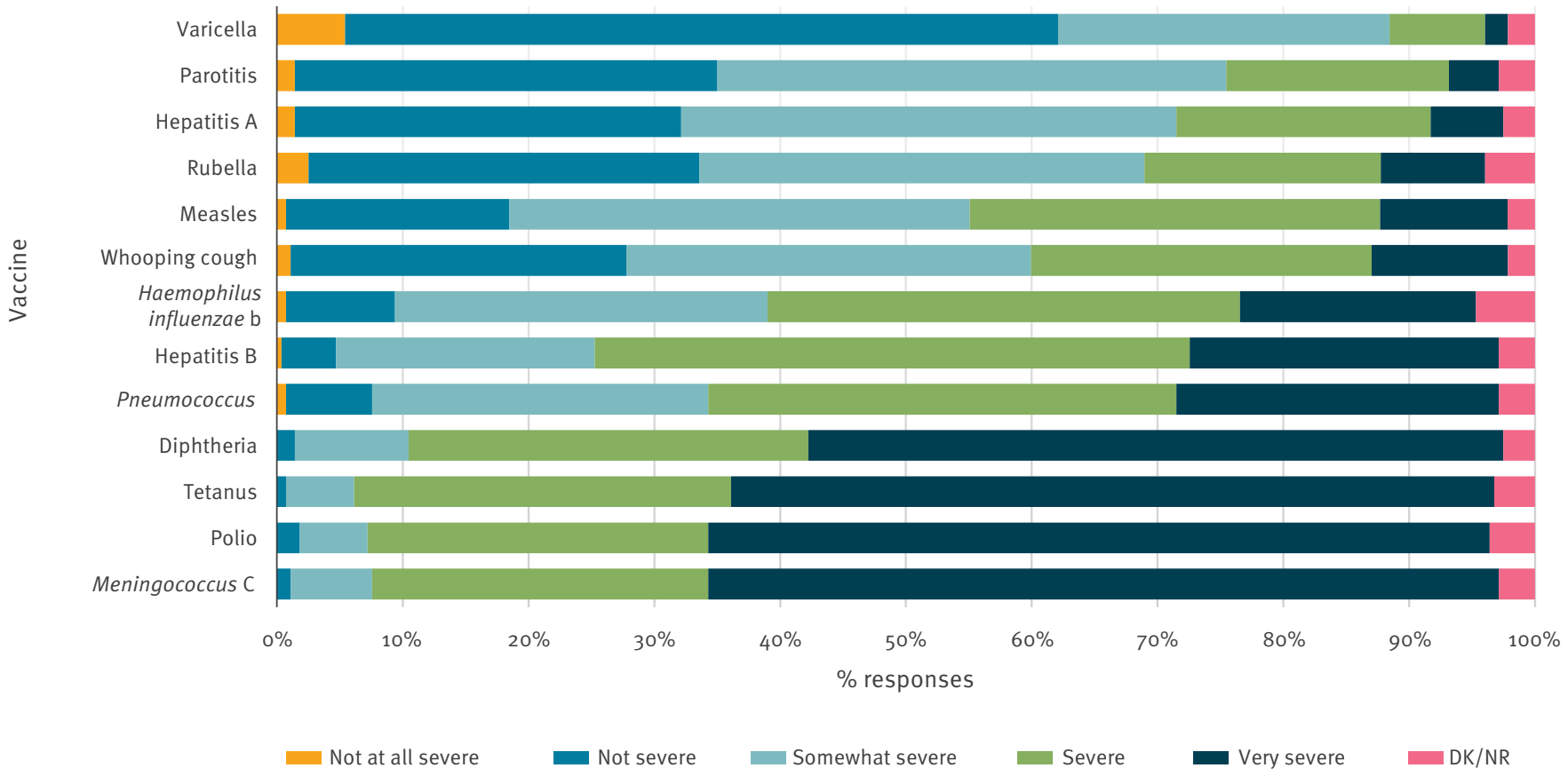

DK/NR: don't know/no response. 


\section{FIGURE 3}

Vaccine safety and effectiveness perceived by paediatric health professionals, survey about vaccine knowledge, attitudes and beliefs, Barcelona, 2016/17 $(\mathrm{n}=277)$

"How safe do you consider the following vaccines?"

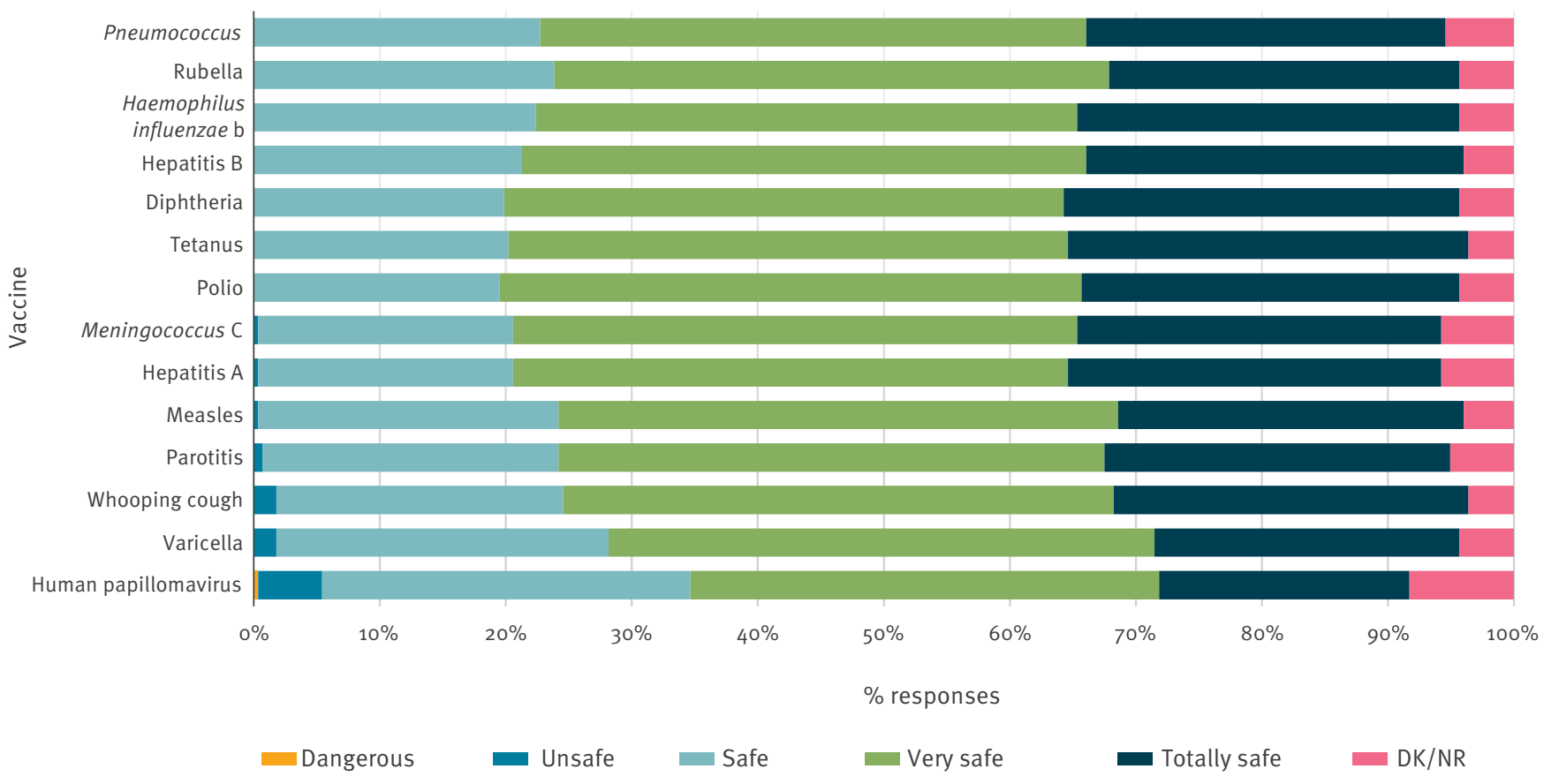

"What degree of protection do you believe the following vaccines offer?"

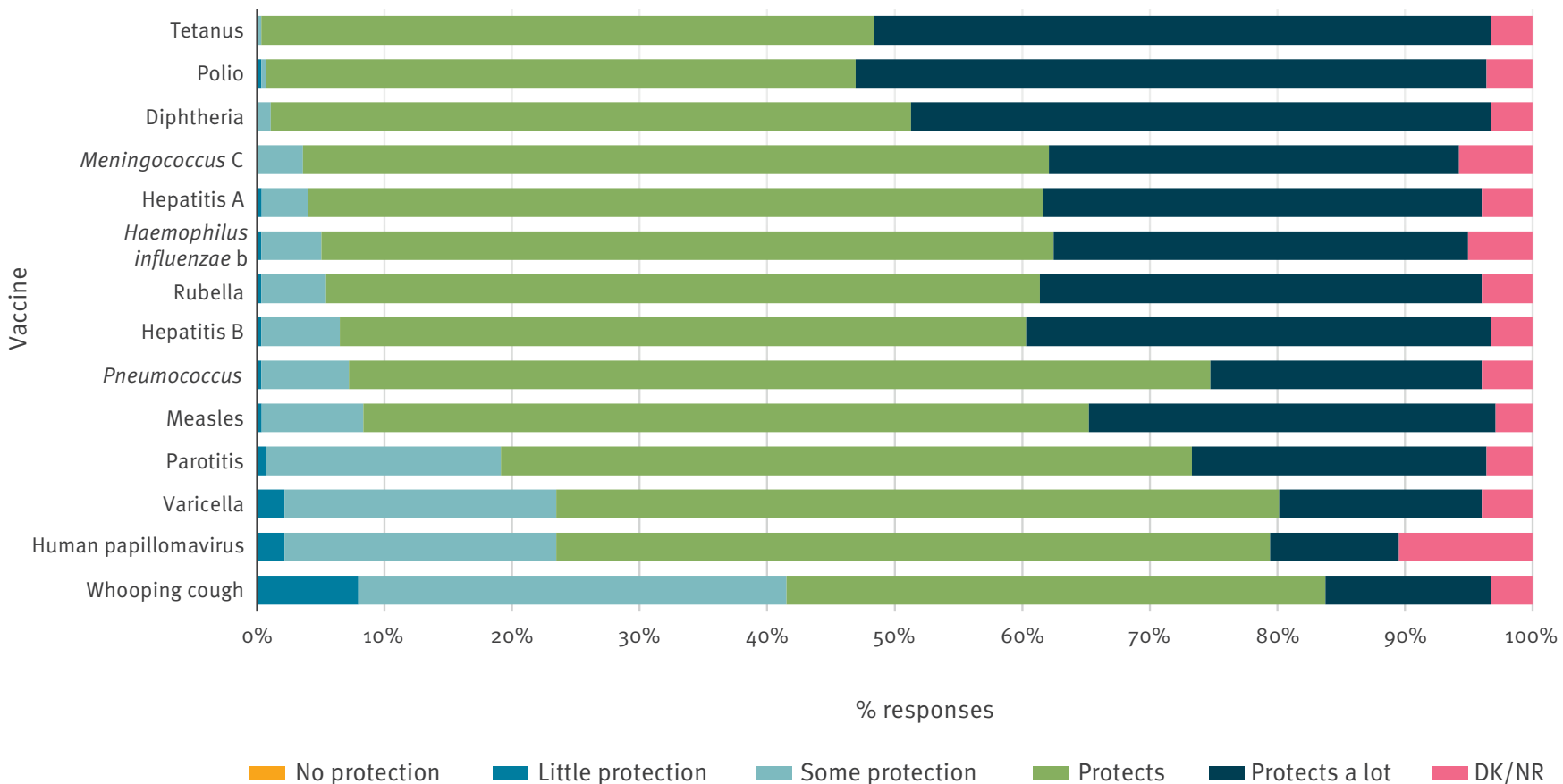

DK/NR: don’t know/no response. 


\section{FIGURE 4}

Key beliefs, knowledge and social norms about vaccines, by affirmation, survey among paediatric health professionals, Barcelona, 2016/17 $(n=277)$

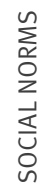

The people in my immediate environment are in favour of vaccination Having an egg allergy is a contraindication for the MMR vaccine The amount of aluminium in vaccines can cause neurotoxicity At least one vaccination in the vaccination calendar contains aluminium

The amount of thiomersal in vaccines can cause neurotoxicity

At least one vaccination in the vaccination calendar contains thiomersal

The varicella vaccine can be a cause of attenuated varicella

The MMR vaccine can be a cause of autism

I believe that the vaccines in the current vaccination calendar are influenced by illegitimate pharmaceutical interests

I believe that the vaccines in the current vaccination calendar are influenced by illegitimate governmental interests

I believe that at least one of the vaccines in the current vaccination calendar is administered too early

Continuing to vaccinate children against polio in Spain is acceptable, even though it has been eliminated from the country

It is better for children to develop immunity by having the illness than through vaccination

Vaccines strengthen the immune system

Thanks to scientific research, vaccines are increasingly better and effective

Vaccines are one of the safest sanitary measures that exist

I am more likely to trust vaccines that have been around longer, compared with newer vaccines It worries me that the immune systems of children could be weakened by receiving an excess amount of vaccines

Children receive more vaccines than they need

Children should only be vaccinated for serious illnesses

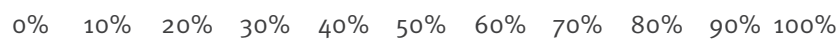

$\%$ responses

Non-vaccine-hesitant option

Vaccine-hesitant option Missing values

MMR: measles-mumps-rubella vaccine.

Responses to key vaccine knowledge, beliefs and social norms were categorised as either vaccine-hesitant or non-vaccine hesitant. 
2016 and ended in February 2017. Some centres were contacted up to six times.

\section{Variables}

Demographical variables were collected. All other variable responses were categorised on a 5-point Likert scale that was later dichotomised. Responses to whether or not they would vaccinate their children against the listed vaccines included in the calendar were dichotomised into 'yes' and the outcome variable 'vaccine doubts' which was a combination of all other options (late/doubts/no). Disease susceptibility and severity variables were dichotomised into 'likely/very likely' vs all other responses and 'severe/very severe' vs all other responses. Vaccine safety was dichotomised into 'safe/very safe/completely safe' vs all other responses and vaccine efficacy was dichotomised into 'protects/ protects a lot' vs all other responses. Benefit of vaccination was dichotomised into benefits "considerably/a lot' vs all other responses. Key vaccine beliefs, knowledge and social norms were also dichotomised into the 'vaccine-hesitant' option vs no $\mathrm{VH}$. Because the key affirmations were positive and negative, agreeing with the affirmation was the vaccine-hesitant option in some cases, while in others, disagreeing corresponded to $\mathrm{VH}$. Missing values and don't know/no response (DK/NR) were all treated the same in the analysis.

\section{Data analysis}

Standard descriptive statistics was performed using STATA version 11.0. Mean, standard deviation and Student's t-test were used for quantitative variables and frequency, chi-squared test, and Fisher's exact test were used for qualitative variables. To study sociodemographic correlates with $\mathrm{VH}$, a multiple logistic regression was performed where odds ratios (OR) were obtained with their $95 \%$ confidence intervals (95\% Cl), adjusting for all sociodemographic variables. Missing values and DK/NR were included only in the descriptive analysis. All analyses were based on two-sided $p$ values with statistical significance defined by $p \leq 0.05$.

\section{Ethical considerations}

This study was approved by the ethics committee of the Consorci Parc de Salut Mar de Barcelona. The researchers declare no conflicts of interest.

\section{Results}

Of the 342 paediatric health professionals in the Barcelona public primary care centres, 277 (81\%) participated in the study; 136 were paediatricians, 138 were paediatric nurses and three were not defined. The rate of participation of paediatricians and paediatric nurses was $76.8 \%$ and $83.6 \%$, respectively. Only one PCC chose not to participate. The mean age was 48 years $(S D=10.5$ years) and $244(88.4 \%)$ were female. The mean number of years of experience was 23 years $(\mathrm{SD}=10.5$ years). Of those who responded to the survey, $75(27.1 \%)$ reported not having children.
Of those that were surveyed, 71 (25.6\%; 95\% Cl: $20.8-$ 31.1) had doubts about at least one of the vaccines in the current vaccination calendar. Respondents reported the most doubt regarding the HPV and varicella vaccines (Figure 1, Supplementary Table S1). Excluding the HPV and varicella vaccines, 34 (12.3\%; 95\% Cl: $8.8-$ 16.7) of health professionals reported having a doubt about at least one vaccine in the current calendar.

Statistically significant differences existed between professions for the pneumococcus (3.8\% vs 9.9\%; $p=0.049)$, Hepatitis B (1.5\% vs $7.6 \% ; p=0.034)$ and HPV (9.9\% vs $22.9 \% ; p=0.005)$ vaccines where nurses reported more doubts. Statistically significant differences existed between those with and without children for the varicella vaccine $(12.5 \%$ vs $25.4 \%$; $p=0.012)$ where those without children reported more doubts.

Perception of probability and severity of illness and of vaccine safety and protection

Thirteen (4.7\%) respondents felt that it would be impossible for an unvaccinated and unimmunised child to contract polio and $198(71.5 \%)$ responded that it is probable or very probable for an unvaccinated child to contract HPV. Respondents reported that polio, illness from meningococcus $\mathrm{C}$ and tetanus were the most serious illnesses, with varicella being the least serious (Figure 2, Supplementary Tables S2 and S3). All vaccines were reported to be safe, with the exception of the HPV vaccine, which was described as dangerous by one participant and unsafe by 14 (5\%). Five respondents also reported the varicella and whooping cough vaccines as being unsafe (Figure 3, Supplementary Tables $\mathrm{S}_{4}$ and $\mathrm{S}_{5}$ ). We saw the largest number of missing values for questions surrounding HPV. Eighteen missing values $(6.5 \%)$ were received for HPV susceptibility, 23 (8.3\%) for HPV vaccine safety and $29(10.5 \%)$ for the level of protection the vaccine provides. In general, there were no statistically significant differences in sex, age or years of profession in relation to the variables on probability and severity of illness and on the protection offered by vaccines. Statistically significant differences were seen among those without children who reported more doubts regarding the safety of the HPV vaccine $(11.5 \%$ vs $3 \% ; p=0.019)$. Statistically significant differences between professions were seen in almost every category.

\section{Key vaccine beliefs, knowledge and social norms}

Of the 277 who participated, 269 (97.1\%) believed that the child receiving the vaccine benefits considerably/ benefits a lot from vaccination, 267 (96.4\%) believed that the community benefits considerably/benefits a lot, $256(92.4 \%)$ believed that health personnel benefit considerably/benefit a lot, $253(91.3 \%)$ believed that the government benefits considerably/benefits a lot, and 244 (88.1\%) believed that the pharmaceutical industry benefits considerably/benefits a lot. There were no significant differences regarding the responses to beliefs about the benefits of vaccination. 
Respondents with or without doubts about vaccines who selected the vaccine-hesitant option, survey among paediatric health professionals, Barcelona, 2016/17 $(n=277)$

\begin{tabular}{|c|c|c|c|c|c|}
\hline & \multicolumn{2}{|c|}{$\begin{array}{l}\text { Respondents with doubts } \\
\qquad(\mathrm{n}=71)^{\mathrm{a}}\end{array}$} & \multicolumn{2}{|c|}{$\begin{array}{l}\text { Respondents without } \\
\text { doubts } \\
(n=206)^{\text {a }}\end{array}$} & \multirow[t]{2}{*}{$\mathrm{p}$ value } \\
\hline & $\mathrm{n}$ & $\%$ & $\mathrm{n}$ & $\%$ & \\
\hline Children should only be vaccinated for serious illnesses & 36 & 53.7 & 35 & 17.50 & $<0.001$ \\
\hline Children receive more vaccines than they need & 33 & 47.1 & 24 & 11.94 & $<0.001$ \\
\hline $\begin{array}{l}\text { It worries me that the immune systems of children could be weakened by } \\
\text { receiving an excess amount of vaccines }\end{array}$ & 19 & 27.9 & 17 & 8.46 & $<0.001$ \\
\hline $\begin{array}{l}\text { I am more likely to trust vaccines that have been around longer, } \\
\text { compared with newer vaccines }\end{array}$ & 33 & 47.1 & 66 & 32.67 & 0.030 \\
\hline Vaccines are one of the safest sanitary measures that exist & 10 & 14.5 & 13 & 6.44 & 0.038 \\
\hline $\begin{array}{l}\text { Thanks to scientific research, vaccines are increasingly better and } \\
\text { effective }\end{array}$ & 10 & 14.5 & 11 & 5.45 & 0.015 \\
\hline Vaccines strengthen the immune system & 23 & $34 \cdot 3$ & 33 & 17.19 & 0.003 \\
\hline $\begin{array}{l}\text { It is better for children to develop immunity by having the illness than } \\
\text { through vaccination }\end{array}$ & 24 & 36.3 & 25 & 12.76 & $<0.001$ \\
\hline $\begin{array}{l}\text { Continuing to vaccinate children against polio in Spain is acceptable, } \\
\text { even though it has been eliminated from the country }\end{array}$ & 7 & 10.0 & 9 & 4.59 & 0.102 \\
\hline $\begin{array}{l}\text { I believe that at least one of the vaccines in the current vaccination } \\
\text { calendar is administered too early }\end{array}$ & 36 & 54.5 & 49 & 24.75 & $<0.001$ \\
\hline $\begin{array}{l}\text { I believe that the vaccines in the current vaccination calendar are } \\
\text { influenced by illegitimate governmental interests }\end{array}$ & 40 & 59.7 & 84 & 44.21 & 0.029 \\
\hline $\begin{array}{l}\text { I believe that the vaccines in the current vaccination calendar are } \\
\text { influenced by illegitimate pharmaceutical interests }\end{array}$ & 46 & 68.6 & 91 & 48.40 & 0.004 \\
\hline The MMR vaccine can be a cause of autism & 7 & 10.9 & 9 & 4.57 & 0.065 \\
\hline The varicella vaccine can be a cause of attenuated varicella & 35 & 52.2 & 96 & 48.73 & 0.620 \\
\hline At least one vaccine in the vaccination calendar contains thiomersal & 28 & 70.0 & 65 & 46.43 & 0.009 \\
\hline The amount of thiomersal in vaccines can cause neurotoxicity & 17 & 37.7 & 49 & 32.24 & 0.489 \\
\hline At least one vaccine in the vaccination calendar contains aluminium & 40 & 74.0 & 106 & 67.95 & 0.399 \\
\hline The amount of aluminium in vaccines can cause neurotoxicity & 18 & 31.5 & 46 & 28.75 & 0.688 \\
\hline Having an egg allergy is a contraindication for the MMR vaccine & 12 & 17.6 & 27 & 13.57 & 0.411 \\
\hline The people in my immediate environment are in favour of vaccination & 6 & 8.4 & 3 & 1.50 & 0.011 \\
\hline
\end{tabular}

MMR: measles-mumps-rubella.

${ }^{\text {a }}$ Missing values were excluded.

Of the 229 participants who believed that pharmaceutical companies benefit considerably/benefit a lot from vaccination and responded to the question about illegitimate interests influencing the vaccination calendar, $129(56.3 \%)$ believed that the vaccines currently recommended are influenced by illegitimate pharmaceutical interests compared with 100 (43.7\%) who did not believe this $(p=0.012)$.

Twenty-five (12.8\%) participants who reported having children felt worried that children's immune systems could be weakened from receiving too many vaccines, and 65 (33\%) of these same respondents believed that at least one vaccine in the current calendar is administered too early. A total of 262 (94.6\%) participants reported that the people in their immediate environment were in favour of vaccination and 10 (3.6\%) participants did not believe that thanks to scientific research, vaccines are increasingly better and more effective (Figure 4).
Key vaccine knowledge affirmations showed the highest number of missing values, and a higher percentage of respondents chose the $\mathrm{VH}$ option. A total of $133(48.0 \%)$ respondents correctly responded that the varicella vaccine can cause attenuated varicella. With respect to the components that make up our vaccines today, 93 participants (33.5\%) responded that at least one vaccine in the current vaccination calendar contains thiomersal and 97 (35\%) did not know the answer or chose not to respond. Further, 80 respondents (28.9\%) did not know or chose not to answer the question which stated that the amount of thiomersal in vaccines can cause neurotoxicity. In addition, 67 (24.2\%) did not respond or did not know whether or not vaccines contain traces of aluminium, and 60 (21.7\%) did not know whether or not the amount of aluminium in vaccines causes neurotoxicity (Figure 4 ).

Those with vaccine doubts chose the $\mathrm{VH}$ response option for every single key vaccine belief, knowledge 
and social norm (Table). Of those who had doubts about at least one vaccine in the current vaccination calendar, $60 \%$ responded that they believed that the current vaccines in the calendar were influenced by illegitimate governmental interests $(p=0.029)$. Similarly, of those who had vaccine doubts, $69 \%$ reported believing that the current vaccination calendar was influenced by illegitimate pharmaceutical interests $(p=0.004)$.

Multivariate analysis adjusted for sociodemographic characteristics revealed the profession of nursing to be a risk factor for $\mathrm{VH}(\mathrm{ORa}=2.0 ; 95 \% \mathrm{Cl}: 1.1-3.7)$ and having children as a factor of less risk for $\mathrm{VH}$ $(\mathrm{ORa}=0.5 ; 95 \% \mathrm{Cl}: 0.2-0.9)$.

\section{Professional practice and vaccine doubts}

Overall, $81(29.2 \%)$ of the $277 \mathrm{HCPs}$ responded that they felt they did not have sufficient information and training to adequately answer questions vaccine-hesitant parents may have. The majority of respondents wished to receive more information about vaccines online $145(52.3 \%)$ and through training sessions 139 (50.2\%).

\section{Discussion}

Our study showed that, in general, public paediatric professionals in Barcelona supported vaccination. However, one in four respondents reported having doubts about at least one vaccine in the current recommended childhood vaccination schedule. Half of the doubts expressed were described in association with the HPV and varicella vaccines. Moreover, we identified a lack of trust in the government and the pharmaceutical industry, a lack of knowledge about vaccine components and the belief in certain myths held by vaccine-hesitant parents.

Despite recent attempts in Spain to unify childhood vaccination schedules, different ones coexist: one for each autonomous region. The Catalan recommended vaccination calendar has been changed four times in the past 10 years [17]. The two vaccines which generated the most doubt in our study population were only recently added to the recommended systematic childhood vaccination calendar (HPV in 2008 and varicella in 2016), and their introduction was accompanied by social and scientific criticism. The doubts surrounding these vaccines described in our population can in part be explained by the frequent changes in the vaccination calendar and differing calendars within the country [18]. This lack of confidence in certain vaccines could be highlighting the need to improve communication between those who dictate public health policies and health professionals who directly care for families. Karafillakis et al. described similar scenarios in France and Greece where a lack of trust in the government and pharmaceutical industry could potentially stain the credibility of vaccine information [19].

While the vaccine effectiveness responses we received were in line with available literature [20-22], it is alarming that some health professionals considered vaccines that are being administered to children as unsafe or even dangerous. The large number of missing responses associated with the HPV vaccine indicates a sense of doubt or unawareness about this vaccine's proven safety and efficacy. Karafillakis et al. also described that the HPV vaccine was singled out in their recent study and explain the hesitancy by the fact that it is a new vaccine [19].

Doubts surrounding the vaccine which protects young girls from HPV is in line with the opinions of certain groups [23], but indicating that the varicella, whooping cough and mumps vaccines are also unsafe, potentially indicates an inability to differentiate between vaccine safety and effectiveness, a crucial determinant when educating vaccine-hesitant parents.

Our respondents' perceptions of disease severity and probability were almost identical to those reported by Salmon et al. [12]. In our study, however, the perception of probability of infection varied. Some professionals considered polio virus infection virtually impossible, an opinion that may have consequences. For example, overconfidence in the safety and effectiveness of a vaccine such as the one against polio, a disease assumed to be eliminated in our environment, could prevent an HCP from recommending the vaccine to families who have doubts about it.

We interpret the high rate of missing values and DK/ NR in our study as a gap in specific key vaccine knowledge. Hence, the conclusion can be drawn that HCPs administering vaccines to children in the public health system in Barcelona are lacking crucial information about vaccine components, contraindications and critical general vaccine knowledge. Paterson et al. described that overall, knowledge about particular vaccines, their efficacy and their safety helped build healthcare professionals' own confidence in vaccines and their willingness to recommend them to others [9]. Improving vaccine knowledge among these professionals is crucial for guiding vaccine-hesitant parents and recommending vaccination.

The frequency of vaccine misconceptions in our study was similar to the study by Salmon et al. [12]. A large number of participants chose the $\mathrm{VH}$ response and did not answer questions related to myths that vaccinehesitant parents might ask. Myths could become part of the belief structure of a society and our results suggest that the environment has already influenced the surveyed professionals in the same way as it does vaccine-hesitant families. Addressing this aspect would require working within the socio-cultural context as suggested by Yaqub et al. [2]. These investigators warned of the risks of focusing only on vaccine uptake rates and overlooking the underlying attitudes and beliefs associated with VH. 
One third of those surveyed felt that they do not have sufficient information and training to adequately address questions from vaccine-hesitant parents. We must ensure that health professionals who are in contact with families are adequately informed and are capable of delivering clear and accurate messages to their patients $[18,24]$. To this effect, new and improved training workshops and information material need to be made available as continued education to these healthcare professionals as soon as possible.

Our results must be interpreted in the context of several methodological limitations. While the high response rate is a strength of this study, it can also be seen as a drawback. The response rate, which surpasses those described in other similar studies $[12,14,25]$, was achieved because the surveys were administered in person. This means that the self-reported evaluations may be subject to expectancy bias and complacency bias. In addition, there could have been a sample selection bias because the study examined only those in the public health sector who willingly participated. We are therefore unaware if those who did not wish to participate held more vaccine doubts or not. Nevertheless, we would like to emphasise that this is the first study that addresses this issue in our environment and that it was aimed at the entire population of paediatric primary care professionals in public centres in the city, which account for the majority of vaccinations in Barcelona.

\section{Conclusions}

The data collected has proven useful for understanding $\mathrm{VH}$ in Barcelona and serves as a starting point for continued monitoring of $\mathrm{VH}$ in this large European city. Because differences among paediatricians and paediatric nurses were seen for almost every variable, and profession was the factor most associated with $\mathrm{VH}$, a more detailed analysis by profession is currently underway.

In a time where other sources of information could potentially outweigh the importance of primary healthcare workers, it is crucial that those involved in the systematic administration of childhood vaccines are equipped with the skills and resources needed to manage the growing issue of $\mathrm{VH}$.

\section{Acknowledgements}

We would like to thank all respondents who took the time to participate in our study. In addition, we would like to thank the reviewers, editors and colleagues who have critically reviewed our paper and provided constructive criticism.

\section{Conflict of interest}

None declared.
Authors' contributions

MSV, MGC and CR created the questionnaire that was administered. MGC contacted each centre to set up a time and date and MGC, MSV, CR and CAP travelled to each centre to administer the questionnaires. Data analysis was performed by CAP using STATA. CAP, MGC and CR actively participated in discussion of results and key ideas for the article, and wrote and edited the article.

\section{References}

1. MacDonald NESAGE Working Group on Vaccine Hesitancy. Vaccine hesitancy: Definition, scope and determinants. Vaccine. 2015;33(34):4161-4. https://doi.org/10.1016/j. vaccine.2015.04.036 PMID: 25896383

2. Yaqub 0, Castle-Clarke S, Sevdalis N, Chataway J. Attitudes to vaccination: a critical review. Soc Sci Med. 2014;112:111. https://doi.org/10.1016/j.socscimed.2014.04.018 PMID: 24788111

3. World Health Organization Regional Office for Europe (WHO/ Europe). Europe observes a 4 -fold increase in measles cases in 2017 compared to previous year. Copenhagen: WHO/ Europe; 2018. Available from: http://www.euro.who.int/en/ media-centre/sections/press-releases/2018/europe-observesa-4-fold-increase-in-measles-cases-in-2017-compared-toprevious-year

4. European Centre for Diseases Prevention and Control (ECDC). Measles cases in the EU treble in 2017, outbreaks still ongoing. Stockholm: ECDC; 2018. Available from: https://ecdc.europa.eu/en/news-events/ measles-cases-eu-treble-2017-outbreaks-still-ongoing

5. Agència de Salut Pública de Catalunya. [Public Health Agency of Catalonia]. Actualització de casos de xarampió a Barcelona i àrea metropolitana. [Update of measles cases in Barcelona and the metropolitan area]. Barcelona: Public Health Agency of Catalonia; 2017. Catalan. Available from: http://canalsalut. gencat.cat/ca/inici/nota-premsa/?id=298192

6. Dubé E, Laberge C, Guay M, Bramadat P, Roy R, Bettinger J. Vaccine hesitancy: an overview. Hum Vaccin Immunother, 2013;9(8):1763-73. https://doi.org/10.4161/hv.24657 PMID: 23584253

7. Bean SJ, Catania JA. Vaccine perceptions among Oregon health care providers. Qual Health Res. 2013;23(9):1251-66. https:// doi.org/10.1177/1049732313501891 PMID: 23964059

8. Verger P, Fressard L, Collange F, Gautier A, Jestin C, Launay O, et al. Vaccine hesitancy among general practitioners and its determinants during controversies: A national cross-sectional survey in France. EBioMedicine. 2015;2(8):891-7. https://doi. org/10.1016/j.ebiom.2015.06.018 PMID: 26425696

9. Paterson P, Meurice F, Stanberry LR, Glismann S, Rosenthal $\mathrm{SL}$, Larson HJ. Vaccine hesitancy and healthcare providers. Vaccine. 2016;34(52):6700-6. https://doi.org/10.1016/j. vaccine.2016.10.042 PMID: 27810314

10. Navarro Alonso JA, Bernal González PJ, Niguez Carbonell JC. Analysis of factors influencing vaccine uptake: perspective from Spain. Vaccine. 2001;20(Suppl 1):S13-5, discussion S1. https://doi.org/10.1016/S0264-410X(01)00300-0 PMID: 11587802

11. Rey D, Fressard L, Cortaredona S, Bocquier A, Gautier $A$, Peretti-Watel P, et al. Vaccine hesitancy in the French population in 2016, and its association with vaccine uptake and perceived vaccine risk-benefit balance. Euro Surveill. 2018;23(17):17-00816.

12. Salmon DA, Moulton LH, Omer SB, Chace LM, Klassen A, Talebian P, et al. Knowledge, attitudes, and beliefs of school nurses and personnel and associations with nonmedical immunization exemptions. Pediatrics. 2004;113(6):e552-9. https://doi.org/10.1542/peds.113.6.e552 PMID: 15173536

13. Buxton JA, McIntyre CC, Tu AW, Eadie BD, Remple VP, Halperin $B$, et al. Who knows more about immunization?: Survey of public health nurses and physicians. Can Fam Physician. 2013;59(11):e514-21. PMID: 24235210

14. Posfay-Barbe KM, Heininger U, Aebi C, Desgrandchamps D, Vaudaux B, Siegrist CA. How do physicians immunize their own children? Differences among pediatricians and nonpediatricians. Pediatrics. 2005;116(5):e623-33. https://doi. org/10.1542/peds.2005-0885 PMID: 16263976

15. Nixon A, Wild D, Muhlhausen W. Patient reported outcomes. An overview. 1st ed. Torino: SEEd; 2015.

16. Language Scientific. Cognitive debriefing explained. Medford: Language Scientific. [Accessed: 24 Jul 2018]. 
Available from: http://www.languagescientific.com/ cognitive-debriefing-explained/

17. Programa de Vacunacions de Catalunya. [Vaccination Program of Catalonia]. Manual de vacunacions de Catalunya. [Manual of vaccinations in Catalonia]. Barcelona: Agència de Salut Pública de Catalunya; 2018. Catalan. Available from: http:// salutpublica.gencat.cat/web/.content/minisite/aspcat/ promocio_salut/vacunacions/oomanual_de_vacunacions/ Manual-de-vacunacions.pdf

18. Black S, Rappuoli R.A crisis of public confidence in vaccines. Sci Transl Med. 2010;2(61):61mr1.

19. Karafillakis E, Dinca I, Apfel F, Cecconi S, Würz A, Takacs J, et al. Vaccine hesitancy among healthcare workers in Europe: A qualitative study. Vaccine. 2016;34(41):5013-20. https://doi. org/10.1016/j.vaccine.2016.08.029 PMID: 27576074

20. Chit A, Zivaripiran H, Shin T, Lee JKH, Tomovici A, Macina D, et al. Acellular pertussis vaccines effectiveness over time: A systematic review, meta-analysis and modeling study. PLoS One. 2018;13(6):e0197970. https://doi.org/10.1371/journal. pone.0197970 PMID: 29912887

21. Wendelboe AM, Van Rie A, Salmaso S, Englund JA. Duration of immunity against pertussis after natural infection or vaccination. Pediatr Infect Dis J. 2005;24(5) Suppl;S58-61. https://doi.org/10.1097/01.inf.0000160914.59160.41 PMID: 15876927

22. Navarro-Illana P, Diez-Domingo J, Navarro-Illana E, Tuells J, Alemán S, Puig-Barberá J. "Knowledge and attitudes of Spanish adolescent girls towards human papillomavirus infection: where to intervene to improve vaccination coverage". BMC Public Health. 2014;14(1):490. https://doi. org/10.1186/1471-2458-14-490 PMID: 24885391

23. McRee AL, Gilkey MB, Dempsey AF. HPV vaccine hesitancy: findings from a statewide survey of health care providers. J Pediatr Health Care. 2014;28(6):541-9. https://doi. org/10.1016/j.pedhc.2014.05.003 PMID: 25017939

24. Larson HJ, Cooper LZ, Eskola J, Katz SL, Ratzan S. Addressing the vaccine confidence gap. Lancet. 2011;378(9790):52635. https://doi.org/10.1016/S0140-6736(11)60678-8 PMID: 21664679

25. Petousis-Harris H, Goodyear-Smith F, Turner N, Soe B. Family physician perspectives on barriers to childhood immunisation. Vaccine. 2004;22(17-18):2340-4. https://doi.org/10.1016/j. vaccine.2003.10.037 PMID: 15149794

\section{License and copyright}

This is an open-access article distributed under the terms of the Creative Commons Attribution (CC BY 4.0) Licence. You may share and adapt the material, but must give appropriate credit to the source, provide a link to the licence, and indicate if changes were made.

This article is copyright of the authors or their affiliated institutions, 2019. 